\title{
Rehabilitation single tooth loss with screw retained implant crown: Case report
}

\author{
Jane Amelia Vebriani Wibisono ${ }^{1}$ \\ ${ }^{1}$ Prosthodontic Departement, Faculty of Dentistry Maranatha Christian University, \\ Indonesia
}

\begin{abstract}
Tooth loss is a common problem in adults. the negative effects of tooth loss are decreased chewing and speech function, reduced aesthetics, and migration of adjacent teeth. Many types of dental prosthetics can be used to prevent these negative effects, such as removable partial dentures, adhesive resin dentures, fixed partial dentures, and dental implants each prosthesis had its advantages and disadvantages. In this case report the clinician will discuss about single tooth implants. The aim of this case report is to provide information about single tooth implant placement to the posterior mandibular teeth using the screw retained implant technique.
\end{abstract}

Key words: Implant, single tooth implant, screw retained implant

\section{Introduction}

Implant supported fixed restorations are common in contemporary dental practice with predictable long-term success. ${ }^{1,2}$ Implant on posterior quadrant removed the disadvantage of crown and bridge fixed partial dentures which challenged the support available from teeth, the retention and resistance form of abutments and the limitations of the materials available to fabricate these prostheses. ${ }^{3}$

There are two different methods of retaining a fixed implant supported restoration: restoration can be secured to implant with screws (screw-retained), or be can be cemented to abutments which are attached to implant with screws (cement retained). 4,5 Deciding on which retention system to use generally occurs during the planning stage when the advantages and disadvantages of each system are considered based on the proposed treatment. ${ }^{6}$

The factors that are affected by different methods of retention of the prostheses to the implants are: ease of fabrication and cost, esthetics, access, occlusion, retention, incidence of loss of retention, retrievability, passivity of fit, restriction of implant position, effect on periimplant tissue health, 
provisionalization, immediate loading, impression procedures, porcelain fracture, and clinical performance., ${ }^{4,5}$

\section{Case report}

A woman, 25 years old came to dental hospital with chief complain was loss of the lower right posterior tooth since 4 years ago because of decay. She never use a prosthesis before. The patient had no systemic disease and in healthy condition. Extraoral examination showed no abnormalities, while intraoral examination was found the loss of tooth 46 (Fig 1c), no calculus was detectedbecause the patient had scalling a month ago, and no decay was found at the other teeth. Clinical intraoral picture, panoramic radiographic (Fig 2), and CBCT (Fig 3) were taken, then alginate impression was done to get study model. On this study model, the artificial tooth was arranged the, then surgical guide from shellac was formed.

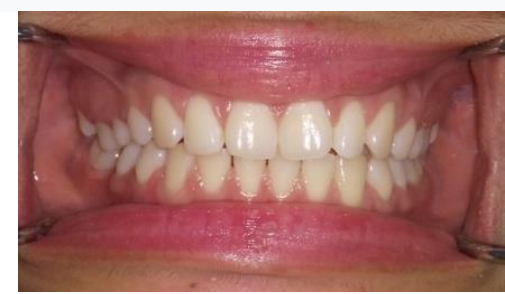

(a)

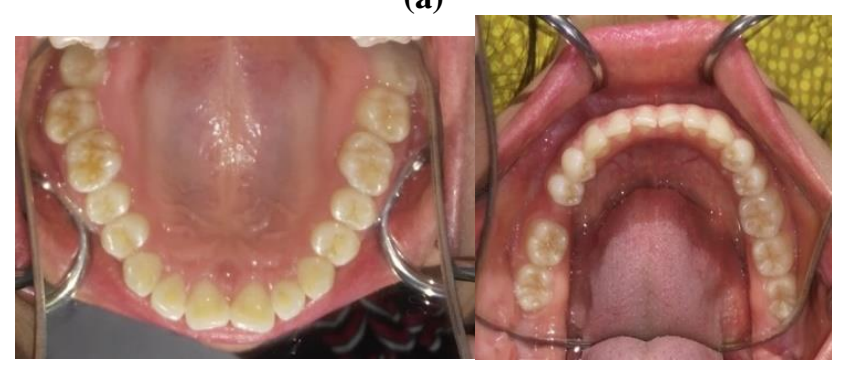

(b)

(c)

Fig 1(a)Labial view, (b)Upper jaw occlusal view, (c)Lower jaw occlusal view

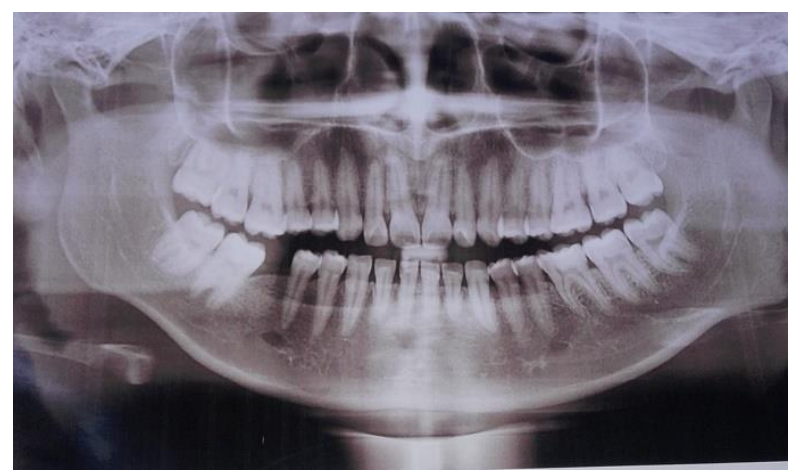

Fig 2. Panoramic radiographic 


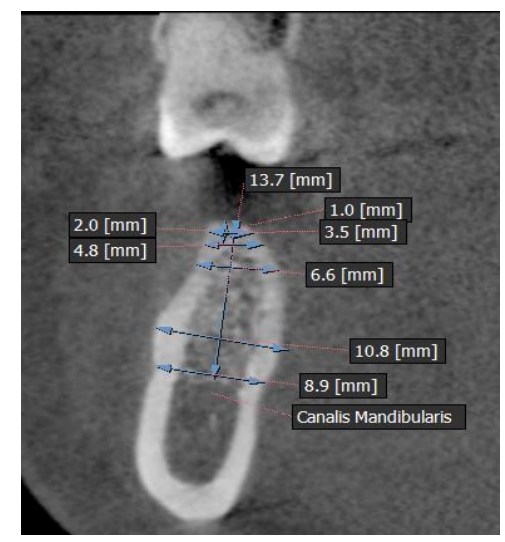

(a)

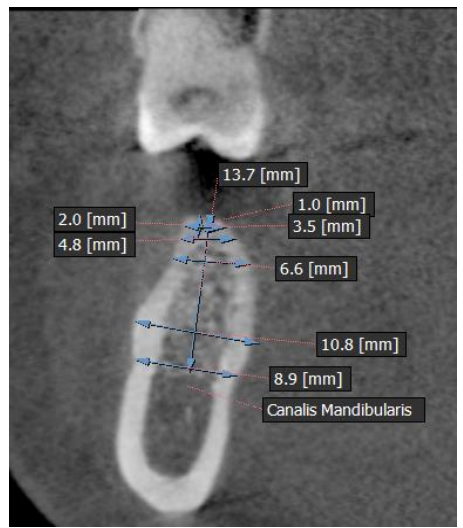

(b)

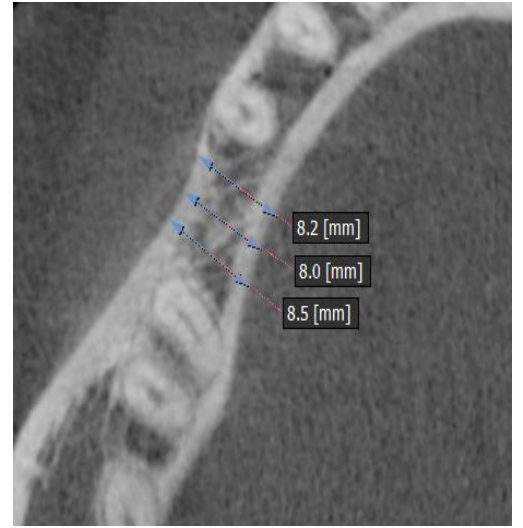

(c)

Fig 3(a)CBCT coronal view, (b)CBCT sagital view, (c)CBCT axial view

CBCT coronal view obtained the buccolingual thickness $1 \mathrm{~mm}$ from alveolar crest was $3,5 \mathrm{~mm}$, the buccolingual thickness $2 \mathrm{~mm}$ from alveolar crest was $4,8 \mathrm{~mm}$. The distance of the alveolar crest to the canal is $13,7 \mathrm{~mm}$. The outer cortex of the buccolingual is $10,8 \mathrm{~mm}$, the buccolingual thickness above the canal was $8,9 \mathrm{~mm}$, and the buccolingual thickness in the crest area was $6,6 \mathrm{~mm}$ (Fig 3a). On CBCT sagital view obtained the distance between adjacent teeth was $6,3 \mathrm{~mm}$, the distance from antagonist teeth to alveolar bone was $5 \mathrm{~mm}$, the distance from alveolar crest to canalis mandibula was $14 \mathrm{~mm}$ and 13,3 mm (Fig 3b). On CBCT axial view obtained the distance outer cortical plate was $8,2 \mathrm{~mm}, 8,0 \mathrm{~mm}$, and 8,5 mm (Fig 3c).

The clinician decided to put 3,5 $\mathrm{mm}$ diameter and 8,5 $\mathrm{mm}$ length fixture (Fig 4a) and two stage surgery (Fig 4b). After the fixture was implanted and cover screw was placed then the gingiva was sewn back up and we waited for 4 months. 
After 1 week the suture were removed. Then after 4 months the incision was made and healing abutment was placed for 2 weeks (Fig 5a) to form emergence profile (Fig 5b).

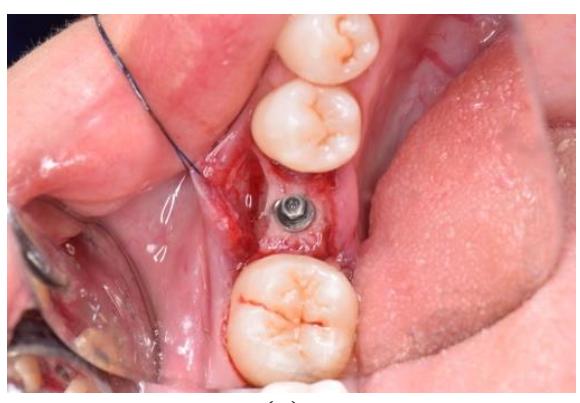

(a)

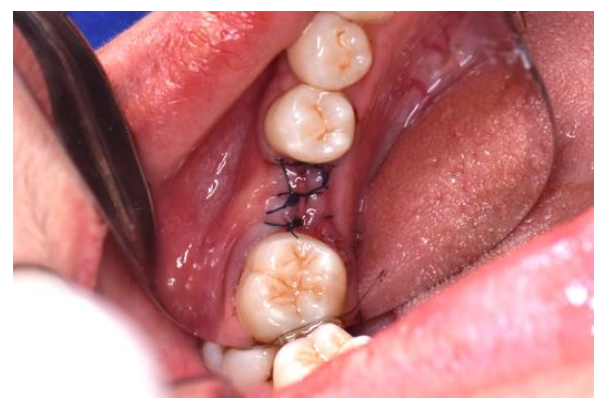

(b)

Fig 4(a) Placement of fixture, (b)operation area was sewn back up

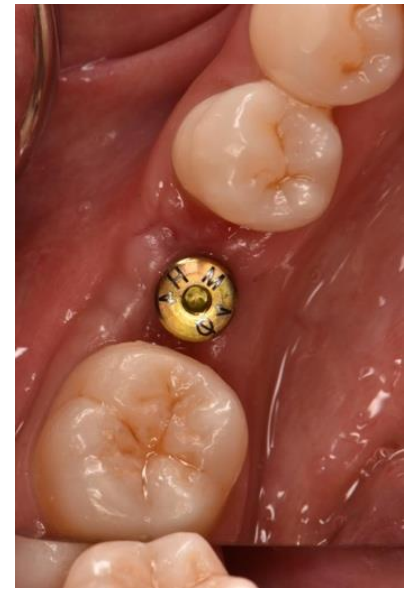

(a)

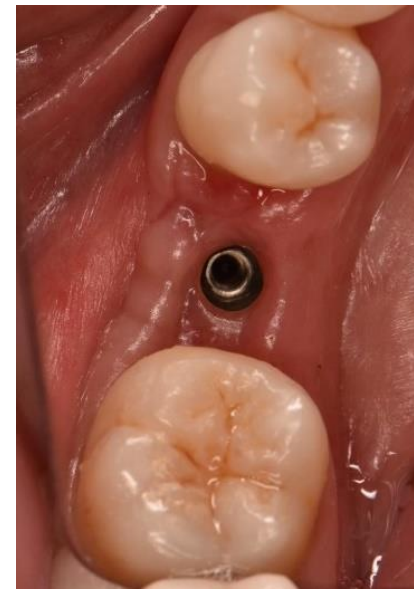

(b)

Fig 5(a) Placement of healing abutment, (b)emergence profile

After the emergence profile was formed, an impression was made with polyvinyl siloxane. In this case the clinician used closed tray impression technique because the span of edentulous area was short. The healing abutment was removed and impression coping was placed and screw hole was closed with temporary restoration material (Fig 6a), then the impression was made. Then implant analog was placed on the impression (Fig 6b). The impression coping was removed and healing abutment was placed. The impression then was sent to the lab and the crown was sent back to clinician (Fig 7). The next appointment to insert the porcelain fused to metal crown. Healing abutment was removed and the crown was screwed to the fixture (Fig 8a), check the occlusion and articulation with articulating paper then screw hole was closed with composite (Fig 8b). After 1 month patient showed no complain and the implant was in good condition. 


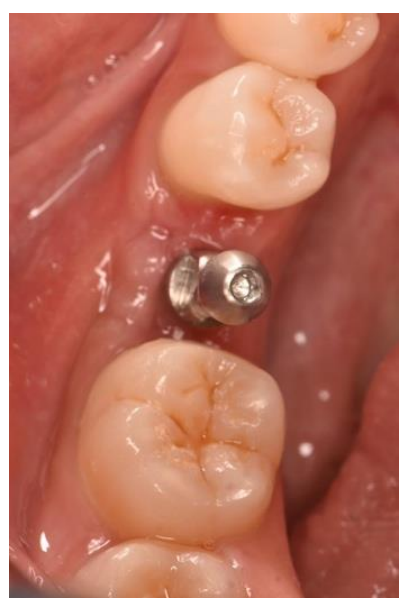

(a)

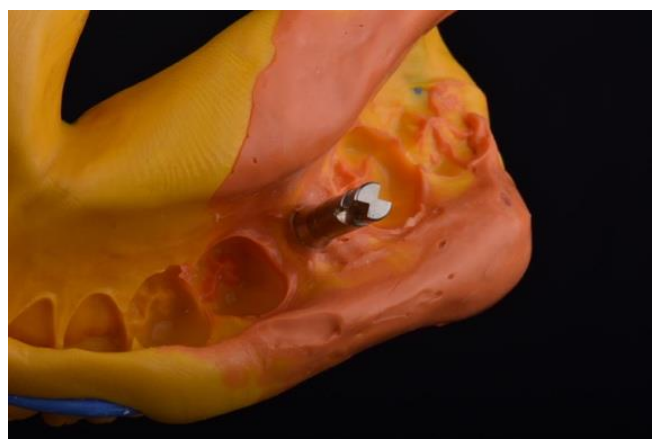

(b)

Fig 6(a) Placement of impression coping, (b)placement of implant analog

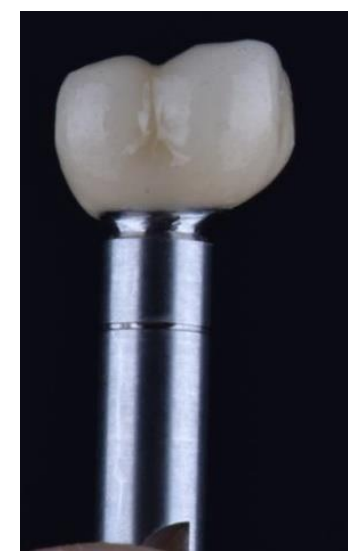

Fig 7. The suprastructure

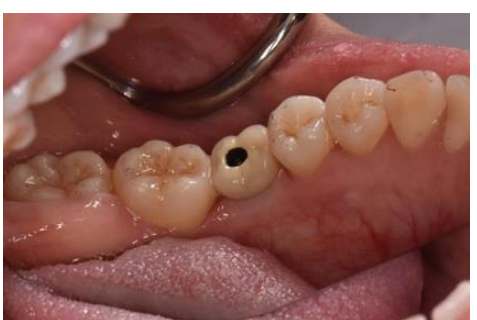

(a)

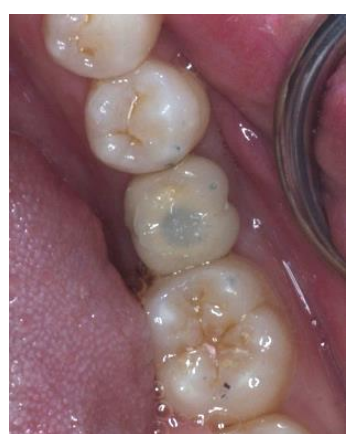

(b)

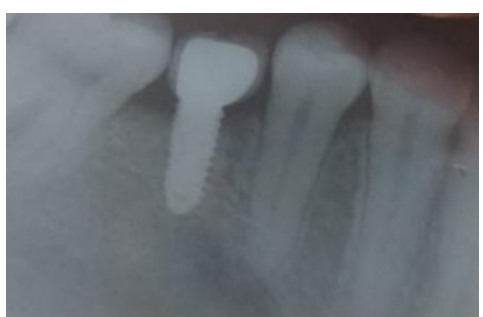

(c)

Fig 8(a) Placement of crown, (b) closing of screw hole with composite, (c) periapical radiograph 


\section{Discussion}

There are many types of prosthesis to fill edentulous area such as removable prosthesis, a resin bonded restoration, a three unit fixed prosthesis, not replacing the tooth, and a single tooth implant. The patient of this case report want a fixed prosthesis without grinding her adjacent teeth. So the clinician decide to use single tooth implant.

There are two techniques in placement of dental implant, screw retained implant and cement retained implant. ${ }^{1-3,5,7,8}$ Advantages of screw retained implant are easy, safe, efficient, retrievable, no cement in soft tissue periimplant area, and retention even for small dimensions. ${ }^{7,9-13}$ Major advantages of screw retained implant was its retrievability. The disadvantages are screw loosening and biological problem with bacteria because implant not perfectly sealed. ${ }^{7,14}$ Screw retained implant crowns demonstrated a significantly lower porcelain fracture resistance than cement retained crowns. ${ }^{15,16}$

The primary use of screws in implant restorations is to fasten prosthetic components together. In most systems a screw is used to fixate the component to the implant body. The primary advantage of a screw retained prosthesis is retention in situations of height, $5 \mathrm{~mm}$ or less. ${ }^{1,7}$ Because the patient not use prosthesis in the past 4 years, there are extrusion on tooth 16 so the distance between tooth 16 and mandibular gingiva was just $5 \mathrm{~mm}$ therefore in this case report the clinician decided to use screw retained implant beside the patient had good oral hygine. After a week, a month and six month implant placement there was no complaint and the patient was satisfied with the treatment and adviced to do periodic control with the clinician.

\section{Conclusion}

Treatment options for single-tooth replacement include a removable prosthesis, a resin bonded restoration, a three unit fixed prosthesis, not replacing the tooth, and a single tooth implant. Single tooth implant provide considerable advantages over removable partial dentures. Implant will improved support, a more stable occlusion, preservation of bone and simplification of the prosthesis, and less invasive over three unit fixed prosthesis. The patient satisfied with the treatment. 


\section{References}

1. Chee W, Jivraj S. Screw versus cemented implant supported restorations. Br Dent J. 2006;201(8):501-7.

2. Nissan J, Narobai D, Gross O, Ghelfan O, Chaushu G. Long-term outcome of cemented versus screw-retained implant-supported partial restorations. Int J Oral Maxillofac Implants [Internet]. 2011;26(5):1102-7. Available from: http://www.ncbi.nlm.nih.gov/pubmed/22010095

3. Jivraj S, Chee W. Treatment planning of implants in posterior quadrants. $\mathrm{Br}$ Dent J. 2006;201(1):13-23.

4. Shadid R, Sadaqa N. A comparison between screw-and cement-retained implant prostheses. A literature review. J Oral Implantol. 2012;38(3):298307.

5. Lee A, Okayasu K, Wang HL. Screw- versus cement-retained implant restorations: Current concepts. Implant Dent. 2010;19(1):8-15.

6. Lemos CAA, De Souza Batista VE, Almeida DADF, Santiago Júnior JF, Verri FR, Pellizzer EP. Evaluation of cement-retained versus screw-retained implant-supported restorations for marginal bone loss A systematic review and meta-analysis. J Prosthet Dent [Internet]. 2016;115(4):419-27. Available from: http://dx.doi.org/10.1016/j.prosdent.2015.08.026

7. Han ES, goleman, daniel; boyatzis, Richard; Mckee A. Dental Implant Prosthetics. Vol. 53, Journal of Chemical Information and Modeling. St. Louis: Elsevier; 2019. 1689-1699 p.

8. Sherif S, Susarla SM, Hwang JW, Weber HP, Wright RF. Clinician- and patient-reported long-term evaluation of screw- and cement-retained implant restorations: A 5-year prospective study. Clin Oral Investig. 2011;15(6):993-9.

9. Weber HP, Kim DM, Ng MW, Hwang JW, Fiorellini JP. Peri-implant softtissue health surrounding cement- and screw-retained implant restorations: A multicenter, 3-year prospective study. Clin Oral Implants Res. 2006;17(4):375-9.

10. Sailer I, Mühlemann S, Zwahlen M, Hämmerle CHF, Schneider D. Cemented and screw-retained implant reconstructions: A systematic review of the survival and complication rates. Clin Oral Implants Res. 2012;23(SUPPL.6):163-201.

11. Rajan M, Gunaseelan R. Fabrication of a cement- and screw-retained implant prosthesis. J Prosthet Dent. 2004;92(6):578-80.

12. Zarone F, Sorrentino R, Traini T, Di lorio D, Caputi S. Fracture resistance of implant-supported screw- versus cement-retained porcelain fused to metal single crowns: SEM fractographic analysis. Dent Mater. 2007;23(3):296301.

13. Vigolo P, Mutinelli S, Givani A, Stellini E. Cemented versus screw-retained implant-supported single-tooth crowns: A 10-year randomised controlled trial. Eur J Oral Implantol. 2012;5(4):355-64.

14. Piattelli A, Scarano A, Paolantonio M, Assenza B, Leghissa GC, Bonaventura $\mathrm{G}$ Di, et al. Fluids and Microbial Penetration in the. J 
SONDE (Sound of Dentistry) Vol 6 No 1

Periodontol. 2001;72(9):1146-50.

15. Torrado E, Ercoli C, Mardini M Al, Graser GN, Tallents RH, Cordaro L. A comparison of the porcelain fracture resistance of screw-retained and cement-retained implant-supported metal-ceramic crowns. J Prosthet Dent. 2004;91(6):532-7.

16. Cicciu M, Bramanti E, Matacena G, Guglielmino E, Risitano G. FEM evaluation of cemented-retained versus screw-retained dental implant singletooth crown prosthesis. Int J Clin Exp Med. 2014;7(4):817-25. 